Revista Brasileira de Agricultura Irrigada v.11, nº.2, p. 1291 - 1301, 2017

ISSN 1982-7679 (On-line)

Fortaleza, CE, INOVAGRI - http://www.inovagri.org.br

DOI: 10.7127/rbai.v11n200606

Protocolo 606.17 - 08/03/2017 Aprovado em 16/03/2017

\title{
CONSUMO DE ÁGUA DE FORRAGEIRAS TROPICAIS NO PERÍODO DE FORMAÇÃO DE PASTAGEM
}

\author{
Arthur Carniato Sanches ${ }^{1}$, Débora Pantojo de Souza ${ }^{2}$, Fernanda Lamede de Ferreira Jesus ${ }^{3}$, \\ Fernando Campos Mendonça ${ }^{4}$, Rodolfo Guertas Maffei $^{5}$
}

\begin{abstract}
RESUMO
O desenvolvimento de estudos que caracterizem o consumo de água de espécies forrageiras de clima tropical tem grande importância, uma vez que há crescente uso da irrigação em pastagens. E soma-se a isso a viabilidade da renovação das pastagens somente em períodos chuvosos. Nesse sentindo, teve-se por objetivo a caracterização do coeficiente de cultura (Kc) e consumo de água para três espécies forrageiras tropicais no período de sua formação e estabelecimento, sendo elas: Brachiaria brizantha cv. Marandu, Cynodon dactylon, Panicum Maximun cv. Mombaça, por um período de 8 semanas. O experimento foi realizado em área experimental da ESALQ/USP, no município de Piracicaba-SP, durante os meses de novembro, dezembro e janeiro de 2015/16. Utilizou-se de lisímetro de pesagem com área superficial de 1,17 $\mathrm{m}^{2}$. A evapotranspiração foi estimada pelo método de Penman-Monteith (Boletim FAO 56). A soma da ETo de todo o período foi de 477,9 mm, com Kc médios dos capins Marandu, Cynodon e Mombaça de 1,07, 0,99 e 1,09; respectivamente. Durante o período os capins apresentaram crescimento dos índices de $\mathrm{Kc}_{\mathrm{s}}$, nos primeiros 8 dias de estabelecimento, com valores menores que 1: 0,9, 0,79 e 0,68 para os capins Marandu, Cynodon e Mombaça, respectivamente. O capim do gênero Panicum foi o que apresentou a maior amplitude do coeficiente de cultura.
\end{abstract}

Palavras-chave: Evapotranspiração, coeficiente de cultura, lisímetros e irrigação por aspersão.

\section{WATER CONSUMPTION OF TROPICAL FORAGE GRASSES IN THE PERIOD OF PASTURE FORMATION}

\footnotetext{
ABSTRACT

The development of studies that characterize the water consumption to forage species tropical is of great importance, since there is increasing use of irrigation in pastures. In addition to that the viability of the renewal of pasture can only exist during rainy periods. In that sense, had to

${ }^{1}$ ESALQ/USP/Doutorando em Engenharia de Sistemas Agrícolas, e-mail: arthur_carniato@hotmail.com

${ }^{2}$ ESALQ/USP/Doutoranda em Engenharia de Sistemas Agrícolas, e-mail: dpdsouza@usp.br

${ }^{3}$ ESALQ/USP/Doutoranda em Engenharia de Sistemas Agrícolas, e-mail: fernandalamede@usp.br

${ }^{4}$ ESALQ/USP/Professor Doutor, e-mail: fcmendon@gmail.com

${ }^{5}$ ESAlQ/USP/aluno de graduação em Engenharia Agronômica, e-mail: rodolfo.maffei@usp.br
} 
aim the characterization of the crop coefficient (Kc) and water consumption for three tropical forage species in the period of formation and establishment, as follows: Brachiaria brizantha cv. Marandu, Cynodon ssp. Tifton 85, Panicum Maximum cv. Mombaça for a period of 8 weeks. The experiment was carried out in an experimental area of ESALQ/USP, in PiracicabaSP, during the months of November, December and January 2015/16. It used to weighing lysimeter with surface area of $1.17 \mathrm{~m}^{2}$. The evapotranspiration was estimated by PenmanMonteith method (FAO paper 56). The sum of ETo of the entire period was $477.9 \mathrm{~mm}$, with an average to Kc for grasses Marandu, Tifton 85 and Mombaça 1.07, 0.99 and 1.09; respectively. During the period, the grasses presented growing $K c$ rates in the first eight days of establishment, with values were less than 1: 0.9, 0.79 and 0.68 for the grasses Marandu, Tifton 85 and Mombaça, respectively. The Panicum grass genre showed the biggest amplitude on the crop coefficient.

Keywords: Evapotranspiration, crop coefficient, lysimeters e sprinkler irrigation.

\section{INTRODUÇÃO}

A intensificação da atividade pecuária, diante de pressões ecológicas, fundiárias e até mercadológicas, pressupõe o uso de capins com melhor desempenho e eficiência na utilização dos insumos (DO VALLE et al., 2009). Desta forma, a pecuária encontra-se sob questionamento quanto a sua sustentabilidade ambiental (CHOBTANG et al., 2017), sendo considerada uma das principais responsáveis pelo desmatamento (MUNIZ et al., 2014).

Nesse contexto, a irrigação é uma alternativa para minimizar as perdas de produtividade causadas por períodos de seca prolongada e sazonalidade, aumentando a produtividade média das pastagens (ANTONIEL et al., 2016). Assim como, a evapotranspiração na pastagem, geralmente, excede a precipitação pluvial (CUNHA et al., 2008). No entanto, muitos trabalhos com pastagens tem utilizados a evapotranspiração de referência (ETo) para manejar a irrigação(MATOS et al., 2013; BACK; DUFLOTH, 2014; ANTONIEL et al., 2016) com a falta de informações de evapotranspiração de cultura para pastagens.

Faz-se necessário conhecer também as perdas de água do solo, sejam as relacionadas a evapotranspiração ou aquelas relacionadas com a drenagem e com o escoamento superficial, evidenciando a necessidade de realizar 0 balanço hídrico no solo (DA SILVA et al., 2014). Desta forma, a proposição do coeficiente de cultura $(\mathrm{Kc})$ é considerado um dos mais importantes parâmetros para quantificar o consumo de água no que se refere às relações hídricas (SANTANA et al., 2016).

O Kc é calculado a partir da relação entre evapotranspiração da cultura (ETc) e evapotranspiração de referência (ETo) (PEREIRA et al., 2015). Trabalhos com pastagens tem demonstrado elevados consumos de água com Kc superiores a 1,00 (BARBOSA et al., 2015; ANTONIEL et al., 2016; SANTANA et al., 2016). Barbosa et al. (2015) encontraram para o capim Tanzânia valor máximo de Kc igual 1,20 aos 30 dias após o corte. Já, Santana et al. (2016) propuseram um Kc médio de 1,07 para o Tifton 85.

Sendo assim, o objetivo desse trabalho é fornecer dados de consumo de água em período inicial de cultivo de três espécies tropicais de pastagens através da proposição do coeficiente de cultura de cada uma delas com o uso de lisímetros de pesagem.

\section{MATERIAL E MÉTODOS}

O experimento foi conduzido em Piracicaba-SP, em área experimental situada no campus da ESALQ/USP (Latitude $22^{\circ} 42^{\prime}$ sul e Longitude $47^{\circ} 38^{\prime}$ Oeste, com altitude $546 \mathrm{~m}$ ) entre os meses de outubro de 2015 a janeiro de 2016. O clima da região segundo a classificação de Köppen é do tipo Cwa - Subtropical de Altitude, com verões quentes, geadas pouco frequentes e concentração das chuvas nos meses de verão (KOTTEK et al., 2006). As forrageiras 
utilizadas no trabalho foram os capins Cynodon dactylon, Brachiaria Brizantha cv. Marandu e Panicum maximum cv. Mombaça.

Nos experimentos dos referentes capins Cynodon, Braquiária e Mombaça o valor acumulado de precipitação foi de 425,3, 565,3 e $501,3 \mathrm{~mm}$; respectivamente. A Temperatura mínima registrada no período experimental foi de $15,8^{\circ} \mathrm{C}$ (Figura 1).

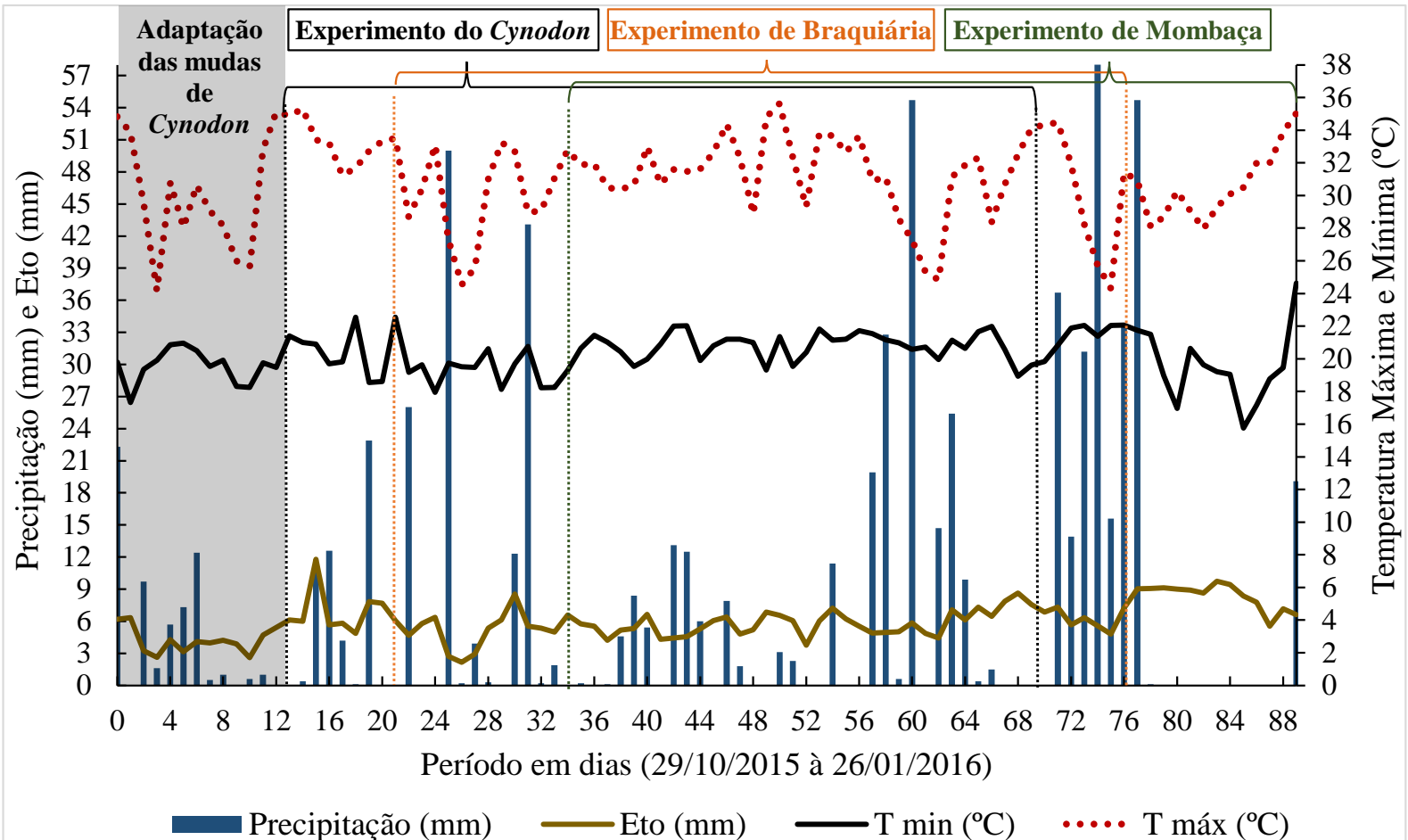

Figura 1. Valores de precipitação $(\mathrm{mm})$, temperatura máxima $\left({ }^{\circ} \mathrm{C}\right)$, temperatura mínima $\left({ }^{\circ} \mathrm{C}\right)$ e Evapotranspiração de Referência (ETo) de 29 de outubro à 26 de janeiro de 2015/16. Piracicaba/SP.

O solo da região é classificado como Nitossolo Vermelho eutroférrico latossólico (SANTOS et al., 2013). Após o preparo convencional do solo, a correção do $\mathrm{pH}$ e adubação de fundação foram realizadas conforme Raij (1997) a partir das análises química e granulométrica do solo é apresentada na Tabela 1.

Tabela 1. Análise química e granulométrica do solo da área experimental na camada de 0 - $20 \mathrm{~cm}, 20$ $40 \mathrm{~cm}$. Piracicaba/SP, 2015.

\begin{tabular}{cccccccccccc}
\hline $\begin{array}{c}\text { camada } \\
\mathrm{cm}\end{array}$ & $\begin{array}{c}\mathrm{pH} \\
\mathrm{CaCl}_{2}\end{array}$ & $\begin{array}{c}\mathrm{P} \\
\mathrm{mg} \mathrm{dm}^{-3}\end{array}$ & $\mathrm{~K}$ & $\mathrm{Ca}$ & $\begin{array}{c}\mathrm{Mg} \\
\mathrm{cmolc} \mathrm{dm}^{-3}\end{array}$ & $\begin{array}{c}\mathrm{H}+\mathrm{Al} \\
\mathrm{Al}\end{array}$ & $\begin{array}{c}\mathrm{CTC} \\
\text { areia } \\
\%\end{array}$ & $\begin{array}{c}\text { silte } \\
\%\end{array}$ & $\begin{array}{c}\text { argila } \\
\%\end{array}$ \\
\hline $0-20$ & 5,3 & 72 & 0,94 & 3,9 & 1,8 & 3,1 & 0,2 & 9,74 & 35,7 & 19,2 & 45,1 \\
$20-40$ & 4,9 & 31 & 0,44 & 1,3 & 1,0 & 4,2 & 0,2 & 6,94 & 29,3 & 18,7 & 52,0 \\
\hline
\end{tabular}

Os capins foram implantados em parcelas de 12 x 12 metros com um lisímetro de pesagem ao centro, em um total de 6 lisímetros (Figura 2). As mudas de Cynodon foram implantadas em 29 de outubro de 2015, e as semeaduras dos capins Braquiária e Mombaça ocorreram em 16 e 29 de novembro de 2015, respectivamente. Cada lisímetro foi composto por uma caixa circular de PVC rígido, com um volume de 500 litros, diâmetro superior de 1,22 m, diâmetro inferior de $1,0 \mathrm{~m}$ e altura de 0,6 $\mathrm{m}$, um sistema de pesagem com células de carga, um sistema de coleta de água e drenagem e uma estrutura de alvenaria para instalação no solo. 


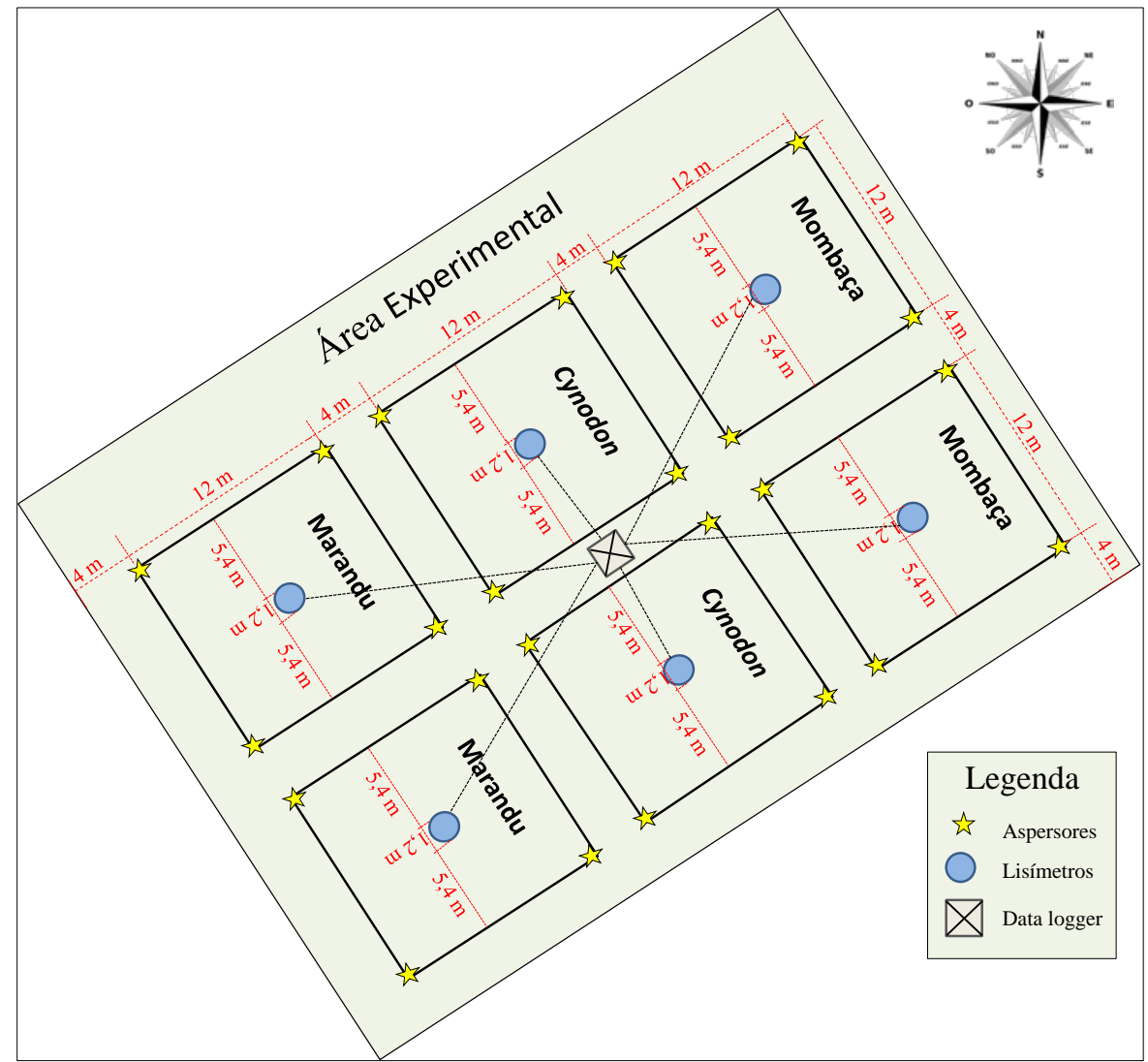

Figura 2. Croqui da área experimental, Piracicaba/SP, 2015/16.

O sistema de irrigação proposto por aspersão convencional, com espaçamento $12 \mathrm{x}$ 12 m (emissores \& linhas), e o tempo de irrigação foi variável, de acordo com o consumo de água das culturas, medido nos lisímetros, e a intensidade de aplicação dos aspersores (Ia) de $12,3 \mathrm{~mm} \mathrm{~h}^{-1}$ funcionando em 25 mca. A irrigação foi composta por aspersores de baixa vazão do tipo setorial (para restringir a irrigação em ângulo de $90^{\circ}$ ), com vazão de $0,592 \mathrm{~m}^{3} \mathrm{~h}^{-1}$.

$\mathrm{O}$ intervalo de irrigação previamente estabelecido foi em função de um limite de $50 \%$ da umidade da capacidade de campo, segundo Fonseca et al. (2007). Desta forma, a lâmina de irrigação (LI) a ser aplicada foi determinada pela diferença entre a umidade volumétrica na capacidade de campo $\left(\theta_{c c}\right)$ e a umidade volumétrica atual $(\theta i)$, multiplicada pela profundidade efetiva da raiz (Z), igual $400 \mathrm{~m}$. A umidade à capacidade de campo $\left(\theta_{\text {cc }}\right)$ foi considerada como a umidade correspondente ao valor de $\Psi_{m}=0,06$ bar (ANDRADE; STONE, 2011). Os valores de $\theta i$ foram estimados por meio da curva de retenção de água no solo, obtida com o auxílio de extrator de Richards no Laboratório de Solos e Qualidade da Água da ESALQ/USP e ajustada pela equação de Genuchten (1980):

$$
\theta i=0,268+\left[\frac{(0,4934-0,2938)}{\left[1+\left(0,113 \Psi_{m}\right)^{1,3211}\right]^{0,2431}}\right] ;\left(\mathrm{R}^{2}=1,00 \text { e } \mathrm{P}<0,01\right)
$$

Em que:

$\theta i=$ umidade volumétrica atual $\left(\mathrm{cm}^{3} \mathrm{~cm}^{-3}\right)$

$\Psi_{m}=$ potencial matricial atual de água no solo (bar).

Para estudo da evapotranspiração das forrageiras foram utilizados de seis lisímetros de pesagem com células de carga, sendo duas repetições por forrageira, que foram instalados no centro das parcelas. Os lisímetros possuíam 1,2 m de diâmetro e $1 \mathrm{~m}$ de profundidade, e foram instalados previamente à implantação das forrageiras (Figura 3). O tanque lisimétrico foi instalado interna e concentricamente a uma parede de concreto, com um espaço de 
aproximadamente $50 \mathrm{~mm}$ entre eles. Cada tanque lisimétrico foi apoiado em três células de carga, de acordo com a metodologia proposta por Righi (2004). As células de carga utilizadas foram da marca ALFA $^{\circledR}$, modelo I - do tipo Shear Bean com capacidade nominal para 500 $\mathrm{kg}$, as quais, combinadas resultaram em capacidade total de $1.500 \mathrm{~kg}$.

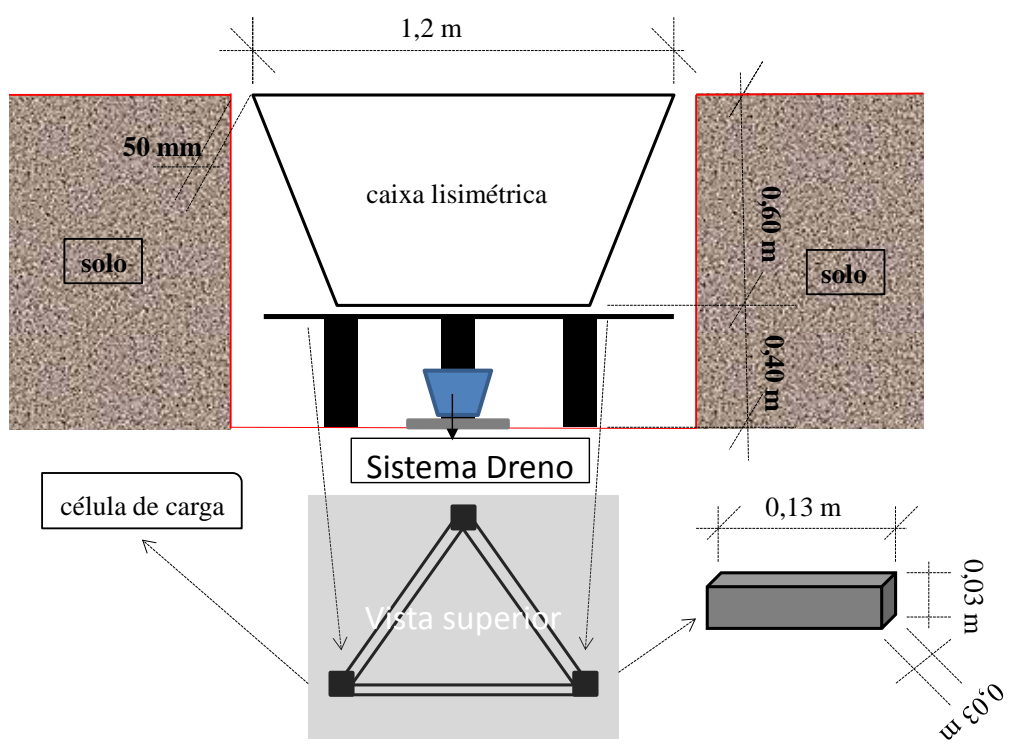

Figura 3. Visão longitudinal do modelo de lisímetro que foi utilizado no experimento. Piracicaba/SP, 2015/16.

As paredes externas dos lisímetros foram construídas em alvenaria com tijolos comum de espessura $0,12 \mathrm{~m}$ para sustentação do solo circundante. O preenchimento do solo nos lisímetros foi feito de maneira a manter as condições iniciais dos horizontes do solo. No centro do fundo da caixa lisimétrica foi desenvolvido um sistema de drenagem automatizado onde foi realizada a drenagem. O volume drenado foi coletado em um reservatório com válvula solenoide apoiado sobre uma célula de carga, também da marca Alfa instrumentos com capacidade para $30 \mathrm{~kg}$, modelo GL30. Os pesos foram registrados a cada 15 minutos, e quando atingido a capacidade máxima de $7,2 \mathrm{~kg}$ previamente calibrada, o volume era liberado reiniciando um novo ciclo de pesagem (Figura 4).

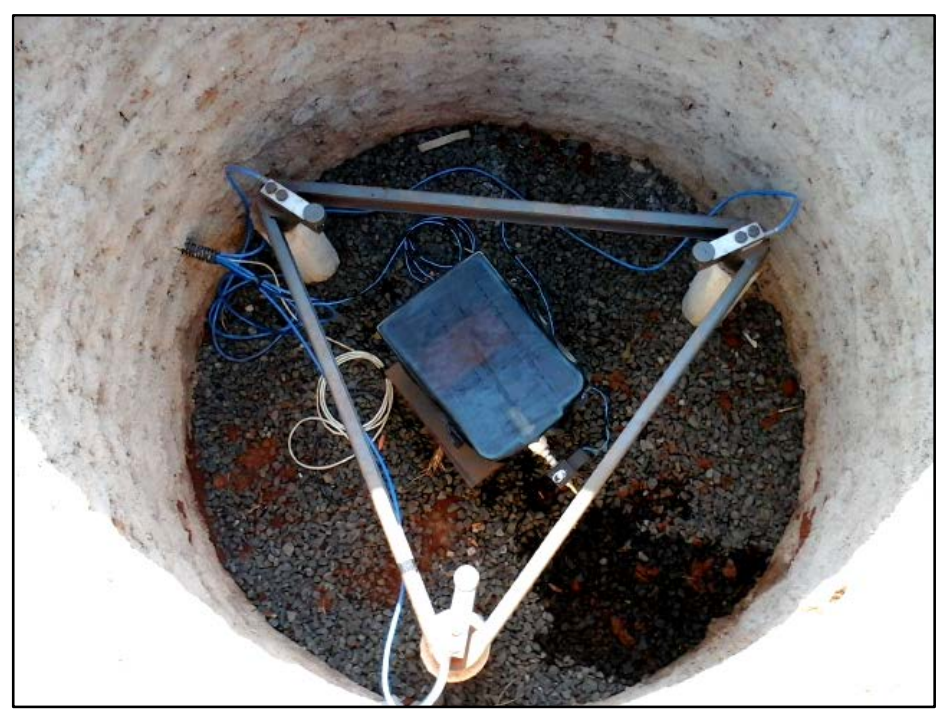

Figura 4. Sistema de pesagem e drenagem. Piracicaba/SP, 2015/16. 
Os sinais de saída das células de carga utilizadas nas medidas lisimétricas foram coletados a cada 10 segundos e suas respectivas médias armazenadas a cada 15 minutos em um sistema de aquisição de dados datalogger, da marca Campbell Scientific ${ }^{\circledR}$, modelo CR1000. O mesmo possuí, entre outras características, oito canais analógicos, três portas de excitação e 4MB de memória interna. Ainda, constou de uma memória extra (cartão de memória removível) de 2G para descarregar os dados em um computador.

A evapotranspiração de referência (ETo) foi obtida a partir da estação meteorológica automática da Esalq/USP que está instalada próxima ao experimento e foi calculada de acordo com a parametrização de Allen et al. (1991) apresentada por Pereira et al. (1997), de acordo com as equações 1 e 2 :

$$
\text { ETo }=\frac{0,408 s(S r-G)+\frac{\gamma 900 U_{2}(e s-e a)}{T+273}}{s+\gamma\left(1+0,34 U_{2}\right)}
$$

Em que,

ETo - evapotranspiração de referência (mm.dia $\left.{ }^{-1}\right)$;

Sr $\quad$ - saldo de radiação em $\left(\mathrm{MJ}^{-\mathrm{m}^{-2}} \cdot \mathrm{dia}^{-1}\right)$;

G - fluxo de calor para o solo $\left(\mathrm{MJ}^{-\mathrm{m}^{-2}}\right.$.dia

$1)$

$\gamma \quad$ - constante psicrométrica $(0,063 \mathrm{kPa}$

$\left.{ }^{\circ} \mathrm{C}^{-1}\right)$;

$\mathrm{U}_{2} \quad$ - velocidade do vento a $2 \mathrm{~m}$ de altura $\left(\mathrm{m} . \mathrm{s}^{-1}\right)$;

es - pressão de saturação de vapor $(\mathrm{kPa})$;

ea - pressão atual de vapor $(\mathrm{kPa})$;

$T$ - temperatura média do ar $\left({ }^{\circ} \mathrm{C}\right)$;

$s \quad$ - variação da pressão de vapor em função da temperatura do $\operatorname{ar}\left(\mathrm{kPa}^{\circ} \mathrm{C}^{-1}\right)$.

$$
s=\frac{4098 s}{(T+237,3)^{2}}
$$

Os dados foram utilizados na escala horária, assim, a Equação 1 sofreu alterações nos coeficientes do numerador $\left(C_{n}=37\right)$ e do denominador $\left(\mathrm{C}_{\mathrm{d}}=0,24\right.$ para $\mathrm{Sr}>0$ e 0,96 para $\mathrm{Sr}<=0$ ), conforme Asce-Ewri (2005) representado na equação 3:

$$
E T o=\frac{0,408 s(S r-G)+\frac{\gamma C_{n} U_{2}(e s-e a)}{T+273}}{s+\gamma\left(1+C_{d} U_{2}\right)}
$$

Para cálculo da evapotranspiração da cultura (ETc), será calculado através das entradas e saídas por diferença de peso do sistema lisimétrico, através da seguinte fórmula:

$$
E T c=V a r m+P+I-V d r e
$$

Em que,

ETc - evapotranspiração da cultura $\left(\mathrm{mm} \mathrm{h}^{-1}\right)$;

Varm - variação de armazenamento $\left(\mathrm{mm} \mathrm{h}^{-1}\right)$;

$\mathrm{P}$ - precipitação $\left(\mathrm{mm} \mathrm{h}^{-1}\right)$;

$\mathrm{I}$ - irrigação $\left(\mathrm{mm} \mathrm{h}^{-1}\right)$;

Vdre - variação de drenagem $\left(\mathrm{mm} \mathrm{h}^{-1}\right)$;

A partir da obtenção dos valores de evapotranspiração da cultura (ETc), da evapotranspiração de referencia (ETo) e da relação ETc/ETo, foram obtidos os valores de coeficiente de cultura (kc) para as forrageiras. Os resultados obtidos foram processados através da planilha eletrônica MS Excel.

\section{RESULTADOS E DISCUSSÃO}

Durante todo o período experimental é possível observar que as chuvas ocorridas foram bem distribuídas (Figura 1), os valores mínimos de temperatura também estiveram acima dos $15^{\circ}$, não havendo restrição ao crescimento das forrageiras. Deste modo, é possível observar que o consumo de água durante o período experimental foi de 323,4, 344,1 e 399,5 mm para os capins Cynodon, Braquiária e Mombaça (Tabela 2). 
Tabela 2. Valores de Evapotranspiração de referência (ETo), Evapotranspiração de cultura (ETc), coeficiente de cultivo (Kc), Precipitação e Temperatura mínima ( $\mathrm{T}$ mín) e máxima ( $\mathrm{T}$ máx). Piracicaba/SP, 2015/16.

\begin{tabular}{lccccccc}
\cline { 3 - 7 } & & $\begin{array}{c}\text { ETo } \\
(\mathrm{mm})\end{array}$ & $\begin{array}{c}\text { ETc } \\
(\mathrm{mm})\end{array}$ & Kc & $\begin{array}{c}\text { Precipitação } \\
(\mathrm{mm})\end{array}$ & $\begin{array}{c}\text { T mín } \\
\left({ }^{\circ} \mathrm{C}\right)\end{array}$ & $\begin{array}{c}\text { T máx } \\
\left({ }^{\circ} \mathrm{C}\right)\end{array}$ \\
\hline \multirow{2}{*}{ Cynodon } & Soma & 326,5 & 323,4 & & 425,3 & & \\
& Média & 5,83 & 5,78 & 0,99 & 7,6 & 20,4 & 31,3 \\
\multirow{3}{*}{ Braquiária } & Soma & 319,8 & 344,1 & & 565,3 & & \\
\multirow{3}{*}{ Mombaça } & Média & 5,7 & 6,1 & 1,07 & 10,1 & 20,6 & 30,9 \\
& Soma & 361,7 & 399,5 & & 501,3 & & \\
& Média & 6,5 & 7,1 & 1,09 & 8,9 & 20,5 & 31,0 \\
\hline
\end{tabular}

Tais valores, menores que as precipitações ocorridas, obtendo um balanço hídrico positivo, cenário contrário à ideia de Cunha et al. (2008) que normalmente ultrapassa a precipitação pluvial. No entanto, o período de experimento é favorável a altas índices pluviométricos para região de Piracicaba.

Com base no princípio de uso da ETo para manejo de irrigação encontrados em alguns trabalhos (MATOS et al., 2013; BACK; DUFLOTH, 2014; ANTONIEL et al., 2016), mostrou-se sensível a incertezas, pois, o trabalho apresentou mesmo em fase de formação de cultura consumo superior para os capins braquiária e Mombaça com $\mathrm{Kc}_{\mathrm{s}}$ médios de 1,07 e 1,09 respectivamente, ou seja, ETc $>$ ETo conforme tabela 2

Conforme Figura 5 pode-se observar a evolução dos $\mathrm{Kc}_{\mathrm{s}}$ ao longo das 8 semanas avaliadas. Pelo princípio da ETo de consumo de água a partir de uma gramínea com altura aproximada de $0,1 \mathrm{~m}$, espera-se que as pastagens tenham comportamento similar, como pode ser observado em cada um dos gráficos a, b e c da figura 5 .
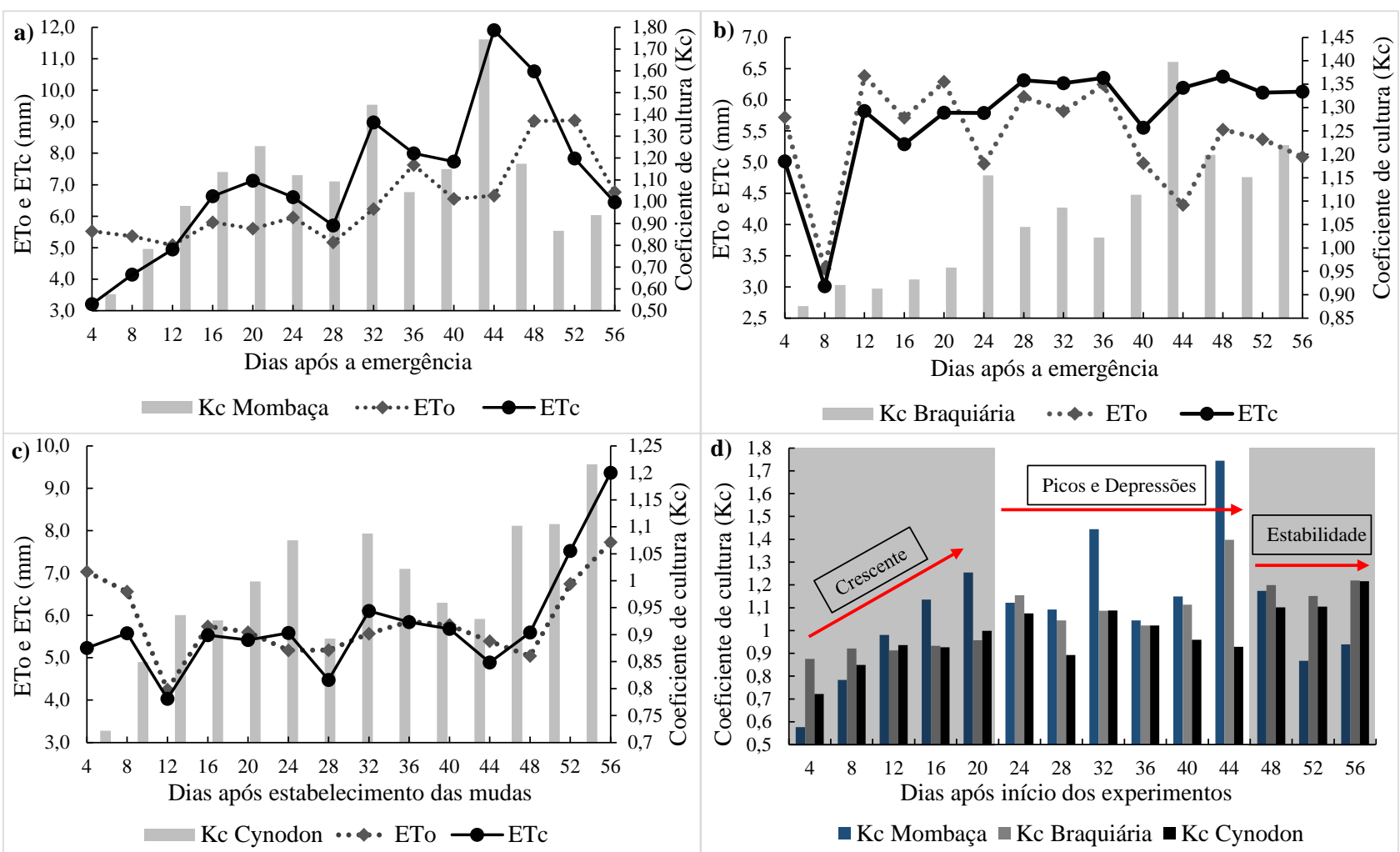

Figura 5. Evolução do Kc (coeficiente de cultura) e da ETc (Evapotranspiração de cultura) para os capins estudados. a) Experimento de capim Mombaça. b) Experimento de braquiária. c) Experimento com capim Cynodon. d) Comparativo dos $\mathrm{Kc}_{\mathrm{s}}$ no período estudado. Piracicaba-SP, 2015/16. 
Em alguns momentos a ETc das pastagens apresentadas é menor que a ETo mensurada, e em outros momentos maior (Figura 5). Verossimilhança ocorre em trabalho de Barbosa et al. (2015) com capim Tânzania, os resultados mostram um Kc inicial pós-corte de 0,64 crescente de até 1,20 aos 30 dias após o corte. Na Mombaça, capim do mesmo gênero, aos 32 dias atinge Kc de 1,4 partindo de 0,58 após a emergência.

No desenvolvimento inicial de culturas, Oliveira et al. (2014) e Lyra et al. (2012) propuseram $\mathrm{Kc}_{\mathrm{s}}$ menores que 1 , de 0,47 e 0,53 para a roseira e a cana-de-açúcar, respectivamente. No trabalho, até 20 dias as pastagens apresentaram média de Kc também menores que 1 , de 0,94, 0,92 e 0,88 para
Mombaça, Braquiária e Cynodon, respectivamente. Foi possível observar o vigor das forrageiras através do rápido crescimento dos $\mathrm{KC}_{\mathrm{s}}$ até os 20 dias, depois um período com alguns picos e ao final uma leve estabilização, mostrando que as pastagens já estavam estabelecidas, conforme Figura 5 d).

Analisando dados meteorológicos médios de algumas localidade do País (Tabela 3) em mesmo período do experimento para o ano 2015 e 2016, é possível observar que apenas o capim braquiária sofreria pequena restrição hídrica para o município de Belo Horizonte em Minas Gerais. Assim, é possível observar que mesmo esse déficit hídrico de $20 \mathrm{~mm}$ aproximadamente poderia não ser significativo para a formação da pastagem.

Tabela 3. Valores de Evapotranspiração de referência (ETo), evapotranspiração de cultura estimado (ETc*) e precipitação pluvial (P) para algumas localidades do país em mesmo período de experimento. Piracicaba/SP, 2015/16.

\begin{tabular}{|c|c|c|c|c|}
\hline & & $\begin{array}{c}\text { ETo } \\
\text { (mm) }\end{array}$ & $\begin{array}{l}\text { ETc* } \\
(\mathrm{mm})\end{array}$ & $\begin{array}{l}\text { Precipitação } \\
\text { (mm) }\end{array}$ \\
\hline \multicolumn{5}{|c|}{ Belém/PA } \\
\hline \multirow{2}{*}{ Cynodon } & Soma & 253,5 & 251 & 359,1 \\
\hline & Média & 4,5 & 4,5 & 6,4 \\
\hline \multirow{2}{*}{ Braquiária } & Soma & 245,2 & 262,3 & 354,4 \\
\hline & Média & 4,4 & 4,7 & 6,3 \\
\hline \multirow{2}{*}{ Mombaça } & Soma & 216 & 235,4 & 519,5 \\
\hline & Média & 3,9 & 4,2 & 9,3 \\
\hline \multicolumn{5}{|c|}{ Belo Horizonte/MG } \\
\hline \multirow{2}{*}{ Cynodon } & Soma & 263 & 260,4 & 360,5 \\
\hline & Média & 4,7 & 4,6 & 6,4 \\
\hline \multirow{2}{*}{ Braquiária } & Soma & 270,9 & 289,8 & 270 \\
\hline & Média & 4,8 & 5,2 & 4,8 \\
\hline \multirow{2}{*}{ Mombaça } & Soma & 254,3 & 277,2 & 456,7 \\
\hline & Média & 4,5 & 4,9 & 8,2 \\
\hline \multicolumn{5}{|c|}{ Jataí/GO } \\
\hline \multirow{2}{*}{ Cynodon } & Soma & 224,9 & 222,7 & 348,4 \\
\hline & Média & 4,0 & 4,0 & 6,2 \\
\hline \multirow{2}{*}{ Braquiária } & Soma & 218,4 & 233,6 & 362,2 \\
\hline & Média & 4,2 & 4,2 & 6,5 \\
\hline \multirow{2}{*}{ Mombaça } & Soma & 240,1 & 240,1 & 376,7 \\
\hline & Média & 4,3 & 4,3 & 6,7 \\
\hline \multicolumn{5}{|c|}{ Matupá/MT } \\
\hline \multirow{2}{*}{ Cynodon } & Soma & 248 & 245,6 & 421,2 \\
\hline & Média & 4,4 & 4,4 & 7,5 \\
\hline \multirow{2}{*}{ Braquiária } & Soma & 235,8 & 252,3 & 516,1 \\
\hline & Média & 4,2 & 4,5 & 9,2 \\
\hline \multirow{2}{*}{ Mombaça } & Soma & 238 & 259,4 & 556,9 \\
\hline & Média & 4,3 & 4,6 & 9,9 \\
\hline \multicolumn{5}{|c|}{ Curitiba/PR } \\
\hline
\end{tabular}




\begin{tabular}{ccccc}
\hline \multirow{2}{*}{ Cynodon } & Soma & 173 & 171,2 & 434,9 \\
& Média & 3,1 & 3,1 & 7,8 \\
\multirow{2}{*}{ Braquiária } & Soma & 175,1 & 187,4 & 500,3 \\
& Média & 3,1 & 3,3 & 8,9 \\
\multirow{2}{*}{ Mombaça } & Soma & 230,9 & 251,7 & 382,6 \\
& Média & 4,1 & 4,5 & 6,8 \\
\hline
\end{tabular}

De tal modo, quando se fala em irrigação de pastagem, ela tem função suplementar em períodos de estiagem e seca prolongada. No caso da formação da pastagem por ser em período de primavera/verão, pouco provável que trará benefícios significativos. No entanto, estudos mais aprofundados devem ser realizados.

\section{CONCLUSÃO}

1. $\mathrm{O} \mathrm{Kc}_{\mathrm{s}}$ das forrageiras apresentaram tendências de aumento nas três primeiras semanas, após isto, verificou comportamentos distintos entre elas. Deve-se adotar $\mathrm{Kc}_{\mathrm{s}}$ distintos durante a fase de crescimento das gramíneas.

2. Os índices médios de $\mathrm{Kc}_{\mathrm{s}}$ ficaram próximos de 1, observando comportamento de Evapotranspiração de cultura semelhantes com a Evapotranspiração de Referência. Sendo que a Mombaça apresentou os maiores picos de Kc, chegando até 1,7 .

3. O consumo de água de todas as forrageiras durante o período experimental ficou abaixo do balanço hídrico, evidenciando a não necessidade de irrigação para a formação de pastagens na região no período de primavera/verão. E mesmo em simulação com outras regiões não foi observado mudanças significativas.

\section{AGRADECIMENTOS}

À Fundação de Amparo à pesquisa do Estado de São Paulo - FAPESP pelo auxílio financeiro do processo 23.002-6/2012 concedido a execução do projeto.

\section{REFERÊNCIAS}

ALLEN, R. G.; HOWELL, T. A.; PRUITT, W. O.; WALTER, I. A.; JENSEN, M.E. (Ed.). Lysimeters for evapotranspiration and environmental measurements. New York: American Society of Civil Engineers, 1991. p. 406-415.

ANDRADE R.D.S.; STONE L.F. Estimativa da umidade na capacidade de campo em solos sob Cerrado. Revista Brasileira de Engenharia Agrícola e Ambiental, v. 15, n. 2, p. 111-116, 2011.

ANTONIEL, L. S.; DO PRADO, G.; TINOS, A. C.; BELTRAME, G. A.; DE ALMEIDA, J. V.; CUCO, G. P. Pasture production under diferente irrigation depths. Revista Brasileira de Engenharia Agrícola e Ambiental, v. 20, n. 6, p. 539-544, 2016.

ASCE-EWRI. The ASCE standardized reference evapotranspiration equation: AsceEwri. Standardization of Reference Evapotranspiration Task Committee Report. Reston: ASCE, 2005.

BACK Á.J.; DUFLOTH J.H. Necessidade de irrigação em pastagens na região de Sombrio, SC. Revista Tecnologia e Ambiente, v.21, p. 270-281, 2014.

BARBOSA B.D.S.; OLIVEIRA F.G.; FIGUEIREDO F.P. DE. Determinação do coeficiente de cultivo (Kc) do capim Tanzânia irrigado no norte de Minas Gerais. Irriga, edição especial, p. 11-20, 2015.

CHOBTANG, J.; LEDGARD, S. F.; MCLAREN, S. J.; DONAGHY, D. J. Life cycle environmental impacts of high and low intensification pasture-based milk production systems: A case study of the Waikato region, 
New Zealand. Journal of Clear Production, v. 140, p. 664-674, 2017.

CUNHA F.F.; SOARES A.A.; MANTOVANI E.C.; SEDIYAMA G.C.; PEREIRA O.G.; ABREU F.V. DE S. Produtividade do capim tanzânia em diferentes níveis e freqüências de irrigação. Acta Sciencitarum Agronomy, v. 30, n. 1, p. 103-108, 2008.

DA SILVA, R. A. B.; DE SOUSA LIMA, J. R.; ANTONINO, A. C. D.; DE SALES GONDIM, P. S.; DE SOUZA, E. S.; JÚNIOR, G. B. Balanço hídrico em Neossolo Regolítico cultivado com braquiária (Brachiária decumbens Stapf). Revista Brasileira de Ciência do Solo, v. 38, n. 1, p. 147-157, 2014.

DO VALLE, C. B.; JANK, L.; RESENDE, R. M. S. O melhoramento de forrageiras tropicais no Brasil. CERES, v. 56, n. 4, 2009.

FONSECA, A. F.; MELFI, A. J.; MONTEIRO, F. A.; MONTES, C. R.; ALMEIDA, V. V. D.; HERPIN, U. Treated sewage effluent as a source of water and nitrogen for Tifton 85 bermudagrass. Agricultural Water Management, v. 87, n. 3, p. 328-336, 2007.

KOTTEK, M.; GRIESER, J.; BECK, C.; RUDOLF, B.; RUBEL, F. World map of the Koppen-Geiger climate classification updated. Meteorologische Zeitshrift, Berlin, v. 15, n. 3, p. 259-263, 2006.

LYRA, G. B.; DA SILVEIRA. E. L.; LYRA, G. B.; PEREIRA, C. R.; DA SILVA, L. D. B.; DA SILVA, G. M. Coeficiente da cultura da canade-açucar no estádio inicial de desenvolvimento em Campos dos Goytacazes, RJ. Irriga, v. 17, n. 1, p. 102, 2012.

MATOS, A. T. D.; SILVA, D. D. F.; MONACO, P. A.; PEREIRA, O. G. Produtividade e composição química do capimTifton 85 submetido a diferentes taxas de aplicação de percolado de resíduo sólido urbano. Engenharia Agrícola, v. 33, n. 1, p. 188-200, 2013.
MUNIZ, R. A.; DE SOUZA; E. F.; MENDONÇA, J. C.; ESTEVES, B. D. S.; LOUSADA, L. D. L. Balanço de Energia e Evapotranspiração do capim Mombaça sob sistema de Pastejo Rotacionado. Revista Brasileira de Meteorologia, v. 29, n. 1, p. 4754, 2014.

OLIVEIRA, E. C.; CARVALHO, J. D. A.; ALMEIDA, E. F.; REZENDE, F. C.; SANTOS, B. D.; MIMURA, S. D. Evapotranspiração da roseira cultivada em ambiente protegido. Revista de Engenharia Agrícola e Ambiental, v. 18, n. 3, p. 314-321, 2014.

PEREIRA, A. R.; VILLA NOVA, N. A.; SEDYAMA, G. C. Evapotranspiração. Piracicaba: FEALQ, 1997, 183p.

PEREIRA L.S.; ALLEN R.G.; SMITH M.; RAES D. Crop evapotranspiration estimation with FAO56: Past and future. Agricuture Water Management, v. 147, p. 4-20, 2015.

RAIJ, B. VAN; CATARELLA, H.; QUAGGIO, J. A.; FURLANI, A. M. C. Recomendações de adubação e calagem para o Estado de São Paulo. 3.ed. Campinas: Instituto Agronômico; Fundação IAC, 1997. 258 p. (Boletim Técnico, 100).

RIGHI, E. Z. Balanço de energia e evapotranspiração de cafezal adensado em crescimento sob irrigação localizada. 2004. 151 p. Tese (Doutorado em Física do Ambiente Agrícola) - Escola Superior de Agricultura “Luiz de Queiroz”, Universidade de São Paulo, Piracicaba, 2004.

SANTANA, M. J.; WACHSMUTH, R.; SGOBI, M. A.; ALMEIDA, F. S. Evapotranspiração e coeficiente de cultura do Tifton 85 em Uberaba, MG. Global Science Technology, v.9, n.3, p.39-50, 2016.

SANTOS, H. G.; JACOMINE, P. K. T.; ANJOS, L. H. C.; OLIVEIRA, V. A. D.; LUMBRERAS, J. F.; COELHO, M. R.; ALMEIDA, J. A.; CUNHA, T. J. F.; OLIVEIRA, J. B. Sistema brasileiro de 
CONSUMO DE ÁGUA DE FORRAGEIRAS TROPICAIS NO PERÍODO DE FORMAÇÃO DE PASTAGEM

classificação de solos. $3^{\mathrm{a}}$ ed. Brasília-DF:

EMBRAPA, 2013.

VAN GENUCHTEN, M. TH. A closed-from equation for predicting the conductivity of unsaturated soils. Soil Science Society of American Journal, Madison, v.44, p. 892-898, 1980. 